\title{
Lung Injury Etiology and Other Factors Influencing the Relationship Between Dead-Space Fraction and Mortality in ARDS
}

\author{
Richard H Kallet MSc RRT FAARC, Hanjing Zhuo MD, Kelly Ho RRT, Michael S Lipnick MD, \\ Antonio Gomez MD, and Michael A Matthay MD
}

\begin{abstract}
BACKGROUND: In ARDS, elevated pulmonary dead-space fraction $\left(V_{D} / V_{T}\right)$ is a particularly strong indicator of mortality risk. Whether the magnitude of $\mathrm{V}_{\mathrm{D}} / \mathrm{V}_{\mathrm{T}}$ is modified by the underlying etiology of ARDS and whether this influences the strength of its association with mortality remains unknown. We sought to elucidate the impact of ARDS etiology on $V_{D} / V_{T}$ and also to determine whether ARDS severity, as classified by the Berlin definition, has correspondence with changes in $V_{\mathrm{D}} / \mathrm{V}_{\mathrm{T}}$. METHODS: This single-center, retrospective, observational study (2010-2016) measured $V_{\mathrm{D}} / \mathrm{V}_{\mathrm{T}}$ in 685 subjects with ARDS as part of clinical management with lung-protective ventilation. Volumetric capnography was used to measure $V_{D} / V_{T}$ with $99 \%$ of measurements occurring within $48 \mathrm{~h}$ of ARDS onset. Demographic information as well as illness severity scores and pulmonary mechanics data also were collected. Multivariate logistic regression modeling was done to assess the strength of association between $V_{D} / V_{T}$ and mortality. RESULTS: $V_{\mathrm{D}} / \mathbf{V}_{\mathrm{T}}$ was elevated across etiologies, with aspiration and pneumonia having significantly higher $V_{D} / V_{T}$ than non-pulmonary sepsis or trauma. Differences in the magnitude of $\mathrm{V}_{\mathrm{D}} / \mathrm{V}_{\mathrm{T}}$ across etiologies did not necessarily correspond with mortality between etiologies. However, within each etiology grouping, $V_{\mathrm{D}} / \mathrm{V}_{\mathrm{T}}$ was significantly elevated in non-survivors versus survivors. The same results were found in both moderate and severe (but not mild) ARDS using the Berlin definition. In the final adjusted model, the strongest mortality risk was $\mathrm{V}_{\mathrm{D}} / \mathrm{V}_{\mathrm{T}}$, wherein the risk of death increased by $22 \%$ for every 0.05 increase in $V_{D} / V_{T}$. CONCLUSIONS: $V_{D} / V_{T}$ magnitude varies by ARDS etiology, as does mortality. Only in mild ARDS does $V_{D} / V_{T}$ fail to distinguish non-survivors from survivors. Nonetheless, $\mathbf{V}_{\mathrm{D}} / \mathbf{V}_{\mathrm{T}}$ has the strongest association with mortality risk in those with ARDS. Key words: ARDS; Berlin definition; mechanical ventilation; physiologic dead-space fraction; single-breath test for carbon dioxide. [Respir Care 2017;62(10):1241-1248. (C) 2017 Daedalus Enterprises]
\end{abstract}

\section{Introduction}

Over the past 15 years, it has been demonstrated that, compared with oxygenation indices, pulmonary dead-space fraction $\left(\mathrm{V}_{\mathrm{D}} / \mathrm{V}_{\mathrm{T}}\right)$ both has a stronger association with mortality in $\mathrm{ARDS}^{1}$ and is a more sensitive marker of changes in pulmonary function in response to therapies aimed at alveolar recruitment. ${ }^{2}$ Left unanswered is the possibility

\footnotetext{
Mr Kallet and Ms Ho are affiliated with Respiratory Care Services, Department of Anesthesia and Perioperative Care, and Dr Gomez is affiliated with the Department of Pulmonary and Critical Care Medicine, University of California San Francisco at Zuckerberg San Francisco General Hospital, San Francisco, California. Drs Zhuo and Matthay are affiliated with the Cardiovascular Research Institute, and Dr Lipnick is affiliated with the Critical Care Division, Department of Anesthesia and Perioperative Care, University of California San Francisco at Zuckerberg San Francisco General Hospital, San Francisco, California.
}

Ms Ho presented this paper in abstract form at the 2016 International Respiratory Congress in San Antonio, Texas.

\begin{abstract}
Mr Kallet discloses relationships with Philips Respironics and Nihon Koden. The other authors have no conflicts to disclose.

Supplementary material related to this paper is available at http:// www.rcjournal.com.

Correspondence: Richard H Kallet MSc RRT FAARC, Department of Anesthesia and Perioperative Care, University of California San Francisco at Zuckerberg San Francisco General Hospital, Bld-5:GA-2, 1001 Potrero Avenue, San Francisco, CA 94110. E-mail: rich.kallet@ucsf.edu.
\end{abstract}

DOI: $10.4187 /$ respcare. 05589 


\section{Dead-Space Fraction and Mortality in ARDS}

that alterations in $\mathrm{V}_{\mathrm{D}} / \mathrm{V}_{\mathrm{T}}$ associated with ARDS, as well as its impact on mortality, may vary according to the etiology of lung injury. This question is based on evidence suggesting that direct versus indirect causes of lung injury

\section{See the Related Editorial on Page 1372}

possess different pathophysiologic characteristics that might impact both the progression and outcome of ARDS. ${ }^{3-5}$ As part of a post hoc analysis, 2 prior studies ${ }^{6,7}$ examined whether $\mathrm{V}_{\mathrm{D}} / \mathrm{V}_{\mathrm{T}}$ differed by ARDS etiology and whether etiology influenced the relationship between impaired $\mathrm{CO}_{2}$ excretion and mortality. Neither study found differences in $\mathrm{V}_{\mathrm{D}} / \mathrm{V}_{\mathrm{T}}$ based either on etiology or its potential impact on mortality. However, both studies may have been inadequately powered (with 59 subjects $^{6}$ and 115 subjects $^{7}$ ) to detect these differences.

In addition, the impact of classifying ARDS according to the Berlin definition ${ }^{8}$ on $\mathrm{V}_{\mathrm{D}} / \mathrm{V}_{\mathrm{T}}$ has not been examined. As with etiology, the previous study by the ARDS Network Clinical Trials Investigators ${ }^{7}$ had an insufficient number of subjects to assess whether the hypoxemia cut-offs used in the Berlin definition altered the relationship between $\mathrm{V}_{\mathrm{D}} / \mathrm{V}_{\mathrm{T}}$ and mortality.

In the current study, our primary objective was to assess the impact of ARDS etiology on both the severity of alterations in $\mathrm{V}_{\mathrm{D}} / \mathrm{V}_{\mathrm{T}}$ and mortality risk. Our secondary objective was to examine whether $\mathrm{V}_{\mathrm{D}} / \mathrm{V}_{\mathrm{T}}$ is influenced by the Berlin definition categories of mild, moderate, and severe ARDS. As done with previous studies, ${ }^{1,7}$ we also examined the overall value of $\mathrm{V}_{\mathrm{D}} / \mathrm{V}_{\mathrm{T}}$ in assessing mortality risk in ARDS compared with other commonly used variables.

\section{Methods}

Data from the 685 study subjects who had dead-space measurements were obtained from our hospital's quality assurance ARDS management database. The database was initiated in September 2000 following publication of the landmark ARDS Clinical Trials Network study ${ }^{9}$ and the decision to implement standardized ventilator protocols for patients with, or at-risk for developing, ARDS. In 2004, the protocol from the ALVEOLI trial ${ }^{10}$ was also incorporated as a management option in our protocol. Volume assist-control ventilation was the primary ventilator mode utilized when implementing these protocols at our facility. However, a minority of subjects were managed with either pressure or dual-mode, continuous mandatory ventilation.

Use of our quality assurance data for research purposes was approved by the University of California San Francisco's institutional review board for human subject protection with waiver of consent granted. Subjects were screened and added to the registry by the Respiratory Care Services quality assurance director only if they met American-European Consensus Conference criteria for ARDS. ${ }^{11}$

\section{QUICK LOOK}

\section{Current knowledge}

Since 2002, several studies have found that elevated pulmonary dead-space fraction $\left(\mathrm{V}_{\mathrm{D}} / \mathrm{V}_{\mathrm{T}}\right)$ is strongly association with mortality in both early and late ARDS. However, previous studies have not been powered to test whether $\mathrm{V}_{\mathrm{D}} / \mathrm{V}_{\mathrm{T}}$ varies according to either ARDS etiology or the newer Berlin definition. Moreover, it's unknown whether any differences in $\mathrm{V}_{\mathrm{D}} / \mathrm{V}_{\mathrm{T}}$ according to these classifications influence its relationship with mortality.

\section{What this paper contributes to our knowledge}

Elevated $\mathrm{V}_{\mathrm{D}} / \mathrm{V}_{\mathrm{T}}$ was associated with increased mortality regardless of ARDS etiology. However, the magnitude of abnormalities in $\mathrm{V}_{\mathrm{D}} / \mathrm{V}_{\mathrm{T}}$ varied according to ARDS etiology, and the associated mortality rate differed among etiologies despite similar $\mathrm{V}_{\mathrm{D}} / \mathrm{V}_{\mathrm{T}}$ values. In addition, only in those classified as having mild ARDS did $\mathrm{V}_{\mathrm{D}} / \mathrm{V}_{\mathrm{T}}$ fail to distinguish non-survivors from survivors.

Subjects were retrospectively reclassified according to the Berlin definition of ARDS. ${ }^{8}$ Each subject's medical record was reviewed to determine the primary source of ARDS and also whether sepsis was a co-diagnosis (when it was not the primary cause of lung injury). All subjects classified with sepsis as the primary source had non-pulmonary origins (predominantly intra-abdominal or from necrotizing fasciitis). Trauma-associated ARDS was classified as being thoracic, non-thoracic, or mixed. These subjects were further differentiated according to the number of organ systems injured (ie, chest, abdomen, orthopedic, brain, soft-tissue/muscle, genital-urinary) and whether subjects received blood products during their resuscitation. Aspiration was assigned as a diagnosis based on either a witnessed event or high suspicion without other discernable causes of lung injury.

\section{Measurements}

Routine measurements of $\mathrm{V}_{\mathrm{D}} / \mathrm{V}_{\mathrm{T}}$ began in early 2010 as part of implementing one of the ARDS Clinical Trials Network ventilator protocols. ${ }^{9,10}$ Measurements of $\mathrm{V}_{\mathrm{D}} / \mathrm{V}_{\mathrm{T}}$ were made within $12 \mathrm{~h}$ of protocol initiation. Ninety-seven percent of measurements occurred on the day of ARDS onset. An additional $2 \%$ of measurements were done within $48 \mathrm{~h}$ of ARDS onset, and the remainder were done within $96 \mathrm{~h}$. An arterial blood gas was drawn simultaneously with mean expired $\mathrm{CO}_{2}\left(\mathrm{P}_{\overline{\mathrm{ECO}}}\right)$ measured by volumetric capnography (NICO monitor, Philips Respironics, Murraysville, Pennsylvania) as described previously. ${ }^{12} \mathrm{~V}_{\mathrm{D}} / \mathrm{V}_{\mathrm{T}}$ was measured using the Enghoff modification of the Bohr equation: $\mathrm{V}_{\mathrm{D}} / \mathrm{V}_{\mathrm{T}}=\left(\mathrm{P}_{\mathrm{aCO}_{2}}-\mathrm{P}_{\overline{\mathrm{ECO}}_{2}}\right) / \mathrm{P}_{\mathrm{aCO}} \cdot{ }^{13}$ 


\section{Dead-Space Fraction and Mortality in ARDS}

Dead-space measurements coincided with a full ventilatorsystems check that included the measurement of expired tidal volume $\left(\mathrm{V}_{\mathrm{T}}\right)$ (both in $\mathrm{mL}$ and relative to predicted body weight according to the ARDS Clinical Trials Network protocol $),{ }^{9}$ end-inspiratory plateau pressure $\left(\mathrm{P}_{\text {plat }}\right)$, PEEP, mean airway pressure, and minute ventilation. Consistent with protocols from prior studies, $1,6,7,12$ assessments were made only when subjects were observed to be calm and synchronous with the ventilator, in the absence of nursing care activities, and, unless contraindicated, in the semi-recumbent position.

Respiratory system compliance was calculated as $\mathrm{V}_{\mathrm{T}} /\left(\mathrm{P}_{\text {plat }}\right.$ - PEEP $)$, which was also recorded to estimate the elastic driving pressure. ${ }^{14}$ Arterial $\mathrm{pH}, \mathrm{P}_{\mathrm{aCO}_{2}}, \mathrm{P}_{\mathrm{aO}}$, base deficit, and $\mathrm{F}_{\mathrm{IO}_{2}}$ were recorded. Measures of oxygenation function included $\mathrm{P}_{\mathrm{aO}_{2}} / \mathrm{F}_{\mathrm{IO}_{2}}$ and the oxygenation index $(\mathrm{OI})$, which was calculated as the product of mean airway pressure and the percent of inspired oxygen divided by $\mathrm{P}_{\mathrm{aO}} \cdot{ }^{15}$

In addition, lung injury score, ${ }^{16}$ Simplified Acute Physiology Score II (SAPS II), ${ }^{17}$ and Acute Physiology and Chronic Health Evaluation II (APACHE II) ${ }^{18}$ score were calculated on the day that protocol management commenced as described previously. ${ }^{19}$ Variables from these scores that were likely to impact outcomes were added to the statistical modeling used to assess mortality risk (eg, the most abnormal value for mean blood pressure, creatinine, blood urea nitrogen, total bilirubin, platelet count, and white blood cell count). For quality assurance purposes, mortality was assessed at the time of hospital discharge.

\section{Statistical Analysis}

Statistical analysis was done using either Stata 9.0 (StataCorp, College Station, Texas) or Instat (GraphPad Software, La Jolla, California). Continuous variables were expressed as mean \pm SD and were compared using either the unpaired Student $t$ test or Mann-Whitney test. Comparisons of continuous variables between ARDS etiologies and Berlin definition categories were done using one-way analysis of variance and Tukey-Kramer post-tests. Categorical variables were compared using Fisher exact tests.

Selected predictor variables that were statistically significant or that were of a priori clinical interest were entered into backward, stepwise, multivariate logistic regression models to test the association of $\mathrm{V}_{\mathrm{D}} / \mathrm{V}_{\mathrm{T}}$ with mortality. For the initial modeling, all variables of interest underwent a univariate analysis. These variables included $\mathrm{V}_{\mathrm{D}} / \mathrm{V}_{\mathrm{T}}$, SAPS II, APACHE II, lung injury score, age, sex, Berlin classification, primary ARDS etiology, sepsis, quartiles of mean blood pressure, creatinine, blood urea nitrogen, total bilirubin, platelet count, $\mathrm{OI}, \mathrm{P}_{\mathrm{aO}} / \mathrm{F}_{\mathrm{IO}}$, respiratory system compliance, $\mathrm{V}_{\mathrm{T}}(\mathrm{mL} / \mathrm{kg}), \mathrm{P}_{\text {plat }}$, and elastic driving pressure $\left(\mathrm{P}_{\text {plat }}-\mathrm{PEEP}\right)$. Those variables achieving a $P<.20$ were added into the initial model. The odds ratio for death was calculated per 0.05 increase in $\mathrm{V}_{\mathrm{D}} / \mathrm{V}_{\mathrm{T}}$, as was done in the original study by Nuckton et al. ${ }^{1}$

\section{Results}

Overall hospital mortality in this ARDS cohort was 38\%, with non-survivors being significantly older and having substantially higher APACHE II, SAPS II, and lung injury scores. Non-survivors were also more likely to have sepsis as a co-diagnosis, more likely to have met standard comorbidity exclusion criteria used by the ARDS Clinical Trials Network studies, ${ }^{9,10}$ more likely to have aspiration, and less likely to have trauma as a primary etiology for ARDS (Table 1). When assessed according to the new Berlin definition, substantially more non-survivors were classified as presenting with severe ARDS compared with survivors, whereas survivors had higher representations of mild and moderate cases.

In addition to having higher lung injury score, nonsurvivors also demonstrated significantly worse gas exchange dysfunction, as evidenced by higher $\mathrm{V}_{\mathrm{D}} / \mathrm{V}_{\mathrm{T}}$ and OI, lower $\mathrm{P}_{\mathrm{aO}_{2}} / \mathrm{F}_{\mathrm{IO}_{2}}$, and arterial $\mathrm{pH}$ with a greater base deficit. In terms of pulmonary mechanics, non-survivors had significantly higher $\mathrm{P}_{\text {plat }}$ and $\mathrm{P}_{\text {plat }}-$ PEEP despite similar $\mathrm{V}_{\mathrm{T}}$, thus resulting in significantly lower respiratory system compliance. Although the higher PEEP level in non-survivors was statistically significant, it was clinically irrelevant.

\section{Impact of ARDS Etiology}

When assessed according to primary ARDS etiology, there was a relatively equal distribution of etiologies, with the most common source being pneumonia (29\%), whereas less common sources (eg, pancreatitis, inhalation injury, etc.) represented $13 \%$ of ARDS cases. ARDS attributed to aspiration and pneumonia was associated with higher $\mathrm{V}_{\mathrm{D}} / \mathrm{V}_{\mathrm{T}}$ and was statistically significant when those with aspiration were compared with those with sepsis, trauma, and other causes. Similar results were found when those with pneumonia were compared with those with sepsis and trauma (Table 2). Within each group, $\mathrm{V}_{\mathrm{D}} / \mathrm{V}_{\mathrm{T}}$ was significantly higher in non-survivors compared with survivors (Fig. 1).

However, differences in $\mathrm{V}_{\mathrm{D}} / \mathrm{V}_{\mathrm{T}}$ between etiologies did not translate into a consistent pattern of hospital mortality (Fig. 2). Particularly salient was the fact that, despite aspiration and pneumonia having similar levels of $\mathrm{V}_{\mathrm{D}} / \mathrm{V}_{\mathrm{T}}$ (67 and $66 \%$, respectively, $P=.14$ ), mortality was substantially lower in pneumonia compared with aspiration (34\% vs $47 \%$, OR 0.80 [0.66-0.98], $P=.03$ ). This was probably accounted for by the fact that subjects with pneumonia versus those with aspiration had significantly lower APACHE II $(22.3 \pm 7.4$ vs $28.7 \pm 8.8$, respectively, $P<.001)$ and SAPS II scores $(49 \pm 16$ vs $60 \pm 19$, respectively, $P<.001)$. Furthermore, even removing subjects with sepsis from the analysis did not alter the mortality difference between these groups (30\% vs $45 \%$ for 


\section{Dead-Space Fraction and Mortality in ARDS}

Table 1. Demographic and Physiologic Characteristics of Non-Survivors and Survivors

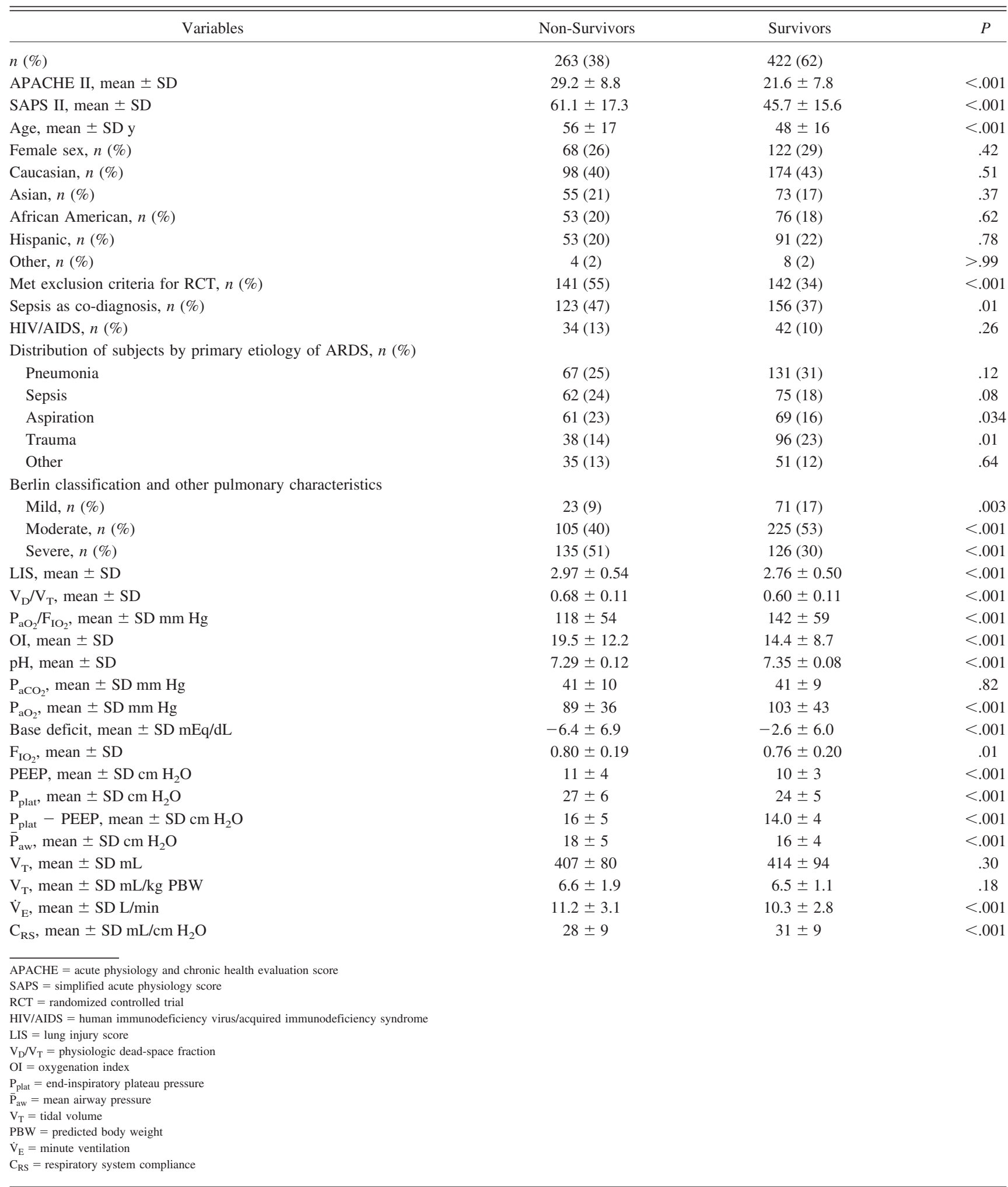


Table 2. Measurements of Pulmonary Function by Sub-Groups of ARDS Etiology

\begin{tabular}{|c|c|c|c|c|c|}
\hline Variables & Aspiration & Pneumonia & Sepsis & Trauma & Other \\
\hline$n(\%)$ & $130(19)$ & $198(29)$ & $137(20)$ & $134(20)$ & $86(13)$ \\
\hline $\mathrm{V}_{\mathrm{D}} / \mathrm{V}_{\mathrm{T}}$, mean $\pm \mathrm{SD}$ & $0.67 \pm 0.12$ & $0.66 \pm 0.10^{*}$ & $0.61 \pm 0.12 \dagger \dagger$ & $0.56 \pm 0.12 \uparrow \S$ & 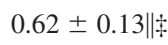 \\
\hline $\mathrm{P}_{\mathrm{aO}_{2}} / \mathrm{F}_{\mathrm{IO}_{2}}$, mean $\pm \mathrm{SD}$ mm Hg & $117 \pm 57 \mathbb{T}^{* *}$ & $130 \pm 57 \uparrow \dagger$ & $139 \pm 56$ & $149 \pm 60$ & $127 \pm 54 \dagger \dagger$ \\
\hline $\mathrm{OI}$, mean $\pm \mathrm{SD}$ & $19.9 \pm 12.3$ & $16.3 \pm 9.6+t$ & $14.1 \pm 7.4 \S \S|\||$ & $14.1 \pm 9.2 \S \S|\||$ & $18.2 \pm 13.5$ \\
\hline $\mathrm{C}_{\mathrm{RS}}$, mean $\pm \mathrm{SD} \mathrm{mL/cm} \mathrm{H}_{2} \mathrm{O}$ & $31 \pm 9$ & $30 \pm 9 \dagger \dagger$ & $30 \pm 10$ & $33 \pm 9$ & $28 \pm 10 \dagger \dagger$ \\
\hline $\mathrm{P}_{\text {plat }}$, mean $\pm \mathrm{SD} \mathrm{cm} \mathrm{H} \mathrm{H}_{2} \mathrm{O}$ & $26 \pm 7 \dagger \dagger$ & $25 \pm 5$ & $25 \pm 5$ & $24 \pm 6$ & $26 \pm 5 \dagger \dagger$ \\
\hline $\mathrm{PEEP}$, mean $\pm \mathrm{SD} \mathrm{cm} \mathrm{H}_{2} \mathrm{O}$ & $11 \pm 4$ & $11 \pm 4$ & $10 \pm 3\||\|\||$ & $11 \pm 4$ & $11 \pm 4$ \\
\hline $\mathrm{P}_{\text {plat }}-\mathrm{PEEP}$, mean $\pm \mathrm{SD} \mathrm{cm} \mathrm{H}_{2} \mathrm{O}$ & $15 \pm 5$ & $15 \pm 4 \dagger \dagger$ & $15 \pm 5 \dagger \dagger$ & $13 \pm 4$ & $15 \pm 4$ \\
\hline $\mathrm{V}_{\mathrm{T}}$, mean $\pm \mathrm{SD} \mathrm{mL} / \mathrm{kg}$ & $6.6 \pm 1.4$ & $6.5 \pm 1.0$ & $6.6 \pm 0.9$ & $6.3 \pm 0.8$ & $6.9 \pm 3.0 \dagger \dagger$ \\
\hline$\dot{\mathrm{V}}_{\mathrm{E}}$, mean $\pm \mathrm{SD} \mathrm{L} / \mathrm{min}$ & $10.9 \pm 3.1$ & $10.7 \pm 3.0$ & $11.1 \pm 2.9 \dagger \dagger$ & $10.0 \pm 2.8$ & $10.3 \pm 2.8$ \\
\hline
\end{tabular}

*P<.001 versus sepsis.

$\dagger P<.001$ versus aspiration.

$\ddagger P<.001$ versus trauma.

$\S P<.001$ versus pneumonia.

$\| P<.01$ versus aspiration.

II $P<.05$ versus sepsis.

$* * P<.001$ versus trauma.

$\dagger P P<.05$ versus trauma.

\$ $P<.05$ versus aspiration

$\S \S P<.01$ versus aspiration.

||| $P<.05$ versus other.

$\mathrm{C}_{\mathrm{RS}}=$ respiratory system compliance

$\mathrm{OI}=$ oxygenation index

$\mathrm{P}_{\mathrm{aO}_{2}} / \mathrm{F}_{\mathrm{IO}_{2}}=$ ratio of arterial oxygen partial pressure-to-inspired oxygen fraction

$\mathrm{P}_{\mathrm{plat}}=$ end-inspiratory plateau pressure

$\mathrm{V}_{\mathrm{D}} / \mathrm{V}_{\mathrm{T}}=$ physiologic dead-space fraction

$\mathrm{V}_{\mathrm{T}}=$ tidal volume

$\dot{\mathrm{V}}_{\mathrm{E}}=$ minute ventilation

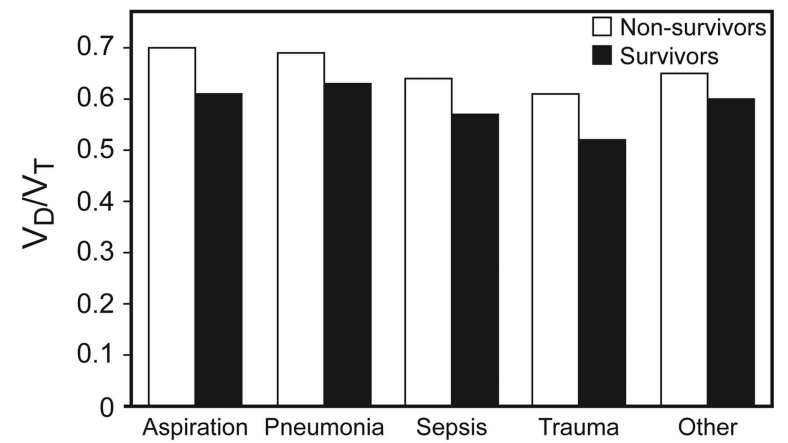

Fig. 1. Differences in dead-space fraction between non-survivors and survivors according to ARDS etiology.

pneumonia and aspiration, respectively, OR 0.53 [0.30-0.95], $P=.042$ ). Moreover, when mortality for each etiologic category was compared with that of the entire study sample, only mortality in trauma-associated ARDS was significantly lower (28\% vs $38 \%$, OR 0.62 [0.41-0.93], $P=.02$ ).

In trauma-associated ARDS, lung injury was categorized as direct (13\%), indirect (20\%), or mixed mechanism $(67 \%)$. However, $\mathrm{V}_{\mathrm{D}} / \mathrm{V}_{\mathrm{T}}$ was not different between injury mechanism $(0.55 \pm 0.11,0.53 \pm 0.09$, and $0.56 \pm 0.12$, respectively, $P=.34$ ). The only salient difference in $\mathrm{V}_{\mathrm{D}} / \mathrm{V}_{\mathrm{T}}$ was found when analyzing subjects according to the number of injured organ systems. Classifying subjects accord-

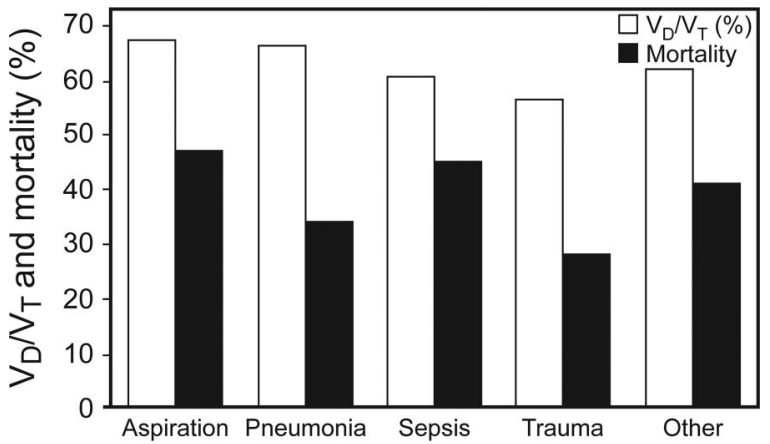

Fig. 2. Comparisons of dead space (expressed as a percentage) and hospital mortality rate according to ARDS etiology.

ingly yielded $\mathrm{V}_{\mathrm{D}} / \mathrm{V}_{\mathrm{T}}$ values of $0.51 \pm 0.09$ (1 system), $0.57 \pm 0.12$ ( 2 systems), $0.56 \pm 0.11$ (3 systems), and $0.60 \pm 0.13$ ( $\geq 4$ systems). $\mathrm{V}_{\mathrm{D}} / \mathrm{V}_{\mathrm{T}}$ was only different between those with 1 versus $\geq 4$ systems $(P=.038)$. Furthermore, only subjects with single-organ system injury (eg, those with chest injury and isolated brain injury) was large enough to allow comparison. Despite the diverse nature of injury mechanism, $\mathrm{V}_{\mathrm{D}} / \mathrm{V}_{\mathrm{T}}$ was not different $(0.50 \pm 0.06$ vs $0.55 \pm 0.09$, respectively, $P=.27)$. In addition, $\mathrm{V}_{\mathrm{D}} / \mathrm{V}_{\mathrm{T}}$ was not different between those requiring transfusions and those who did not $(0.56 \pm 0.12$ vs $0.55 \pm 0.10$, respectively, $P=.31$ ). 


\section{Dead-Space Fraction and Mortality in ARDS}

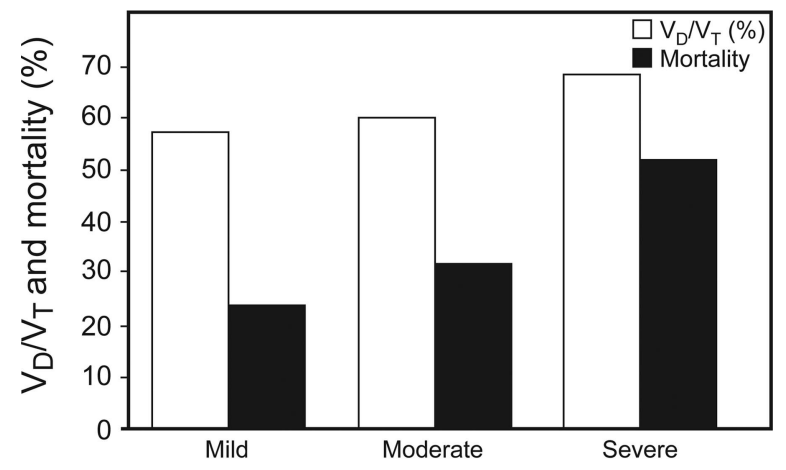

Fig. 3. Comparisons of dead space (expressed as a percentage) and hospital mortality rate according to the Berlin definition of ARDS as either mild, moderate, or severe.

\section{Influence of Berlin Definition}

When assessed by the Berlin definition, both $\mathrm{V}_{\mathrm{D}} / \mathrm{V}_{\mathrm{T}}$ and mortality increased with increasing ARDS severity (Fig. 3 ). Mortality was not significantly different between mild and moderate ARDS ( $24 \%$ vs $32 \%$, respectively, OR 0.69 [0.41-1.17], $P=.20$ ), However, it was significantly higher in subjects with severe versus mild ARDS (52\% vs $24 \%$, respectively, OR 0.30 [0.18-0.51], $P<.001)$ and higher in severe versus moderate ARDS (52\% vs $32 \%$, OR 0.44 [0.31-0.61], $P<.001)$. Likewise, $\mathrm{V}_{\mathrm{D}} / \mathrm{V}_{\mathrm{T}}$ increased significantly with ARDS severity $(P=.03$ for mild vs moderate, and $P<.01$ for both mild vs severe and moderate vs severe). Moreover, differences in $\mathrm{P}_{\text {plat }}$ - PEEP steadily increased between mild, moderate, and severe ARDS $(13 \pm 2,14 \pm 4$, and $16 \pm 5 \mathrm{~cm} \mathrm{H}_{2} \mathrm{O}$, respectively, $P<.001$ ).

When comparisons were made within each Berlin category, $\mathrm{V}_{\mathrm{D}} / \mathrm{V}_{\mathrm{T}}$ was significantly higher among non-survivors only in the moderate and severe groups (Table 3 ). In contrast, $\mathrm{P}_{\mathrm{aO}_{2}} / \mathrm{F}_{\mathrm{IO}_{2}}$ did not differentiate non-survivors from survivors in any of the groups but did approach significance in those with severe ARDS. Similarly, both respiratory system compliance and OI differentiated non-survivors from survivors only in those with severe ARDS. $V_{T}$ was not different between non-survivors and survivors in any of the groups. Differences in $\mathrm{P}_{\text {plat }}$ - PEEP between non-survivors and survivors were only apparent in those with either moderate or severe ARDS (see Table 3).

\section{Influence of Comorbidities}

Non-survivors also were disproportionately characterized as having comorbidities that would disallow their participation in randomized controlled treatment trials for ARDS. Those who met ARDS Clinical Trials Network exclusion criteria had significantly higher SAPS II, APACHE II, and lung injury scores compared with those who met enrollment criteria. However, $\mathrm{V}_{\mathrm{D}} / \mathrm{V}_{\mathrm{T}}$ did not dis-
Table 3. Measurements of Pulmonary Function and Mortality by ARDS Severity

\begin{tabular}{|c|c|c|c|}
\hline Categories and Variables & Non-Survivors & Survivors & $P$ \\
\hline \multicolumn{4}{|l|}{ Mild } \\
\hline $\mathrm{V}_{\mathrm{D}} / \mathrm{V}_{\mathrm{T}}$ & $0.60 \pm 0.10$ & $0.56 \pm 0.12$ & .16 \\
\hline $\mathrm{P}_{\mathrm{aO}_{2}} / \mathrm{F}_{\mathrm{IO}_{2}}, \mathrm{~mm} \mathrm{Hg}$ & $238 \pm 28$ & $240 \pm 30$ & .67 \\
\hline OI & $6.0 \pm 1.9$ & $6.7 \pm 3.8$ & .44 \\
\hline $\mathrm{C}_{\mathrm{RS}}, \mathrm{mL} / \mathrm{cm} \mathrm{H}_{2} \mathrm{O}$ & $34 \pm 11$ & $32 \pm 10$ & .55 \\
\hline $\mathrm{P}_{\text {plat }}-\mathrm{PEEP}, \mathrm{cm} \mathrm{H}_{2} \mathrm{O}$ & $13 \pm 5$ & $13 \pm 4$ & .95 \\
\hline \multicolumn{4}{|l|}{ Moderate } \\
\hline $\mathrm{V}_{\mathrm{D}} / \mathrm{V}_{\mathrm{T}}$ & $0.65 \pm 0.11$ & $0.58 \pm 0.11$ & $<.001$ \\
\hline $\mathrm{P}_{\mathrm{aO}_{2}} / \mathrm{F}_{\mathrm{IO}_{2}}, \mathrm{~mm} \mathrm{Hg}$ & $143 \pm 29$ & $145 \pm 30$ & .64 \\
\hline OI & $12.8 \pm 4.7$ & $11.5 \pm 3.8$ & .13 \\
\hline $\mathrm{C}_{\mathrm{RS}}, \mathrm{mL} / \mathrm{cm} \mathrm{H}_{2} \mathrm{O}$ & $30 \pm 10$ & $32 \pm 10$ & .13 \\
\hline $\mathrm{P}_{\text {plat }}-\mathrm{PEEP}, \mathrm{cm} \mathrm{H}_{2} \mathrm{O}$ & $15 \pm 5$ & $14 \pm 4$ & .03 \\
\hline \multicolumn{4}{|l|}{ Severe } \\
\hline $\mathrm{V}_{\mathrm{D}} / \mathrm{V}_{\mathrm{T}}$ & $0.71 \pm 0.10$ & $0.64 \pm 0.10$ & $<.001$ \\
\hline $\mathrm{P}_{\mathrm{aO}_{2}} / \mathrm{F}_{\mathrm{IO}_{2}}, \mathrm{~mm} \mathrm{Hg}$ & $78 \pm 17$ & $81 \pm 14$ & .09 \\
\hline OI & $27.0 \pm 12.7$ & $23.9 \pm 9.0$ & .02 \\
\hline $\mathrm{C}_{\mathrm{RS}}, \mathrm{mL} / \mathrm{cm} \mathrm{H}_{2} \mathrm{O}$ & $26 \pm 8$ & $30 \pm 8$ & $<.001$ \\
\hline $\mathrm{P}_{\text {plat }}-\mathrm{PEEP}, \mathrm{cm} \mathrm{H}_{2} \mathrm{O}$ & $17 \pm 5$ & $15 \pm 4$ & .004 \\
\hline \multicolumn{4}{|c|}{$\begin{array}{l}\text { Results are mean } \pm \mathrm{S} D \\
\mathrm{~V}_{\mathrm{D}} / \mathrm{V}_{\mathrm{T}}=\text { physiologic dead-space fraction } \\
\mathrm{OI}=\text { oxygenation index }\end{array}$} \\
\hline
\end{tabular}

tinguish those meeting exclusion criteria versus those meeting enrollment criteria (see the supplementary materials at http://www.rcjournal.com).

\section{Dead Space and Mortality}

In the final adjusted model, the significant predictors of mortality included age, SAPS II, and total bilirubin. Pulmonary-specific predictors of mortality included OI, $\mathrm{P}_{\text {plat }}$ - PEEP, and $\mathrm{V}_{\mathrm{D}} / \mathrm{V}_{\mathrm{T}}$ (Table 4). Of these, the strongest association with mortality was $\mathrm{V}_{\mathrm{D}} / \mathrm{V}_{\mathrm{T}}$, where the risk of death increased by $22 \%$ for every 0.05 increase in $\mathrm{V}_{\mathrm{D}} / \mathrm{V}_{\mathrm{T}}(\mathrm{OR}=1.22,95 \%$ CI $1.11-1.35, P<.001)$.

\section{Discussion}

The main finding of the present study is that direct causes of lung injury (aspiration and pneumonia) are associated with significantly higher $\mathrm{V}_{\mathrm{D}} / \mathrm{V}_{\mathrm{T}}$ than indirect causes (non-pulmonary sepsis), and $\mathrm{V}_{\mathrm{D}} / \mathrm{V}_{\mathrm{T}}$ was a significant predictor of mortality in subjects with either direct or indirect etiologies of ARDS. A novel finding was that ARDS etiologies with similar magnitudes of $\mathrm{V}_{\mathrm{D}} / \mathrm{V}_{\mathrm{T}}$ did not demonstrate similar rates of mortality. The most salient of these was the markedly lower mortality among subjects with pneumonia versus aspiration despite small differences in $\mathrm{V}_{\mathrm{D}} / \mathrm{V}_{\mathrm{T}}$. This is probably explained by the fact that those with aspiration were more severely ill, 


\section{Dead-Space Fraction and Mortality in ARDS}

Table 4. Mortality as a Function of Dead-Space Fraction by Both Unadjusted and Adjusted Analyses

\begin{tabular}{|c|c|c|c|}
\hline Models and Variables & $\mathrm{OR}^{*}$ & $95 \% \mathrm{CI}$ & $P$ \\
\hline \multicolumn{4}{|l|}{ Unadjusted } \\
\hline $\mathrm{V}_{\mathrm{D}} / \mathrm{V}_{\mathrm{T}}$ & 1.38 & $1.28-1.49$ & $<.001$ \\
\hline \multicolumn{4}{|l|}{ Adjusted } \\
\hline $\mathrm{V}_{\mathrm{D}} / \mathrm{V}_{\mathrm{T}}$ & 1.22 & $1.11-1.35$ & $<.001$ \\
\hline $\mathrm{P}_{\text {plat }}-\mathrm{PEEP}$ & 1.06 & $1.01-1.10$ & .01 \\
\hline OI & 1.03 & $1.01-1.05$ & .004 \\
\hline Age & 1.03 & $1.02-1.04$ & $<.001$ \\
\hline SAPS II & 1.02 & $1.00-1.04$ & .046 \\
\hline Total bilirubin & 1.02 & $1.01-1.03$ & $<.001$ \\
\hline \multicolumn{4}{|c|}{$\begin{array}{l}\text { * Odds ratio per } 0.05 \text { increase in physiologic dead-space fraction. } \\
\mathrm{V}_{\mathrm{D}} / \mathrm{V}_{\mathrm{T}}=\text { physiologic dead-space fraction } \\
P_{\text {plat }}=\text { end-inspiratory plateau pressure } \\
\mathrm{OI}=\text { oxygenation index } \\
\text { SAPS = simplified acute physiology score }\end{array}$} \\
\hline
\end{tabular}

as indicated by higher APACHE II and SAPS II scores. Moreover, the present study reaffirmed that elevated $V_{D} / V_{T}$ has the strongest association with mortality in subjects with ARDS as compared with numerous other prediction tools and variables. This finding is consistent with our previous reports. ${ }^{1,7}$

When examined according to the Berlin definition, $\mathrm{V}_{\mathrm{D}} / \mathrm{V}_{\mathrm{T}}$ was significantly greater as ARDS severity increased; however, the differences in $\mathrm{V}_{\mathrm{D}} / \mathrm{V}_{\mathrm{T}}$ between mild and moderate forms were minor. This coincided with the fact that mortality was not significantly different between mild and moderate ARDS. Moreover, mild ARDS was the only tested condition wherein $\mathrm{V}_{\mathrm{D}} / \mathrm{V}_{\mathrm{T}}$ did not distinguish non-survivors from survivors.

An explanation for the differences in $\mathrm{V}_{\mathrm{D}} / \mathrm{V}_{\mathrm{T}}$ between ARDS etiologies is not readily apparent. We had previously posited that elevated $\mathrm{V}_{\mathrm{D}} / \mathrm{V}_{\mathrm{T}}$ and its strong association with mortality was probably an indicator of the extent of endothelial injury and pervasive pulmonary vascular obstruction. ${ }^{1,7}$ This in turn might increase the likelihood of developing cor pulmonale, which is known to increase mortality risk in ARDS. ${ }^{20}$ Therefore, it was inviting to predict that ARDS associated with non-pulmonary sepsis would be more likely to exhibit greater derangement in $\mathrm{V}_{\mathrm{D}} / \mathrm{V}_{\mathrm{T}}$ than other causes. However, the results of this study suggest a more complex pathophysiologic process.

The reason why $\mathrm{V}_{\mathrm{D}} / \mathrm{V}_{\mathrm{T}}$ was substantially higher in aspiration and pneumonia versus non-pulmonary sepsis is unclear based upon our data. However, a recent study ${ }^{21}$ of local alveolar gas dynamics in experimental ARDS using advanced microimaging techniques may provide some insight to our finding. Within minutes of inducing ARDS in animal models, the investigators observed the emergence of both pronounced pendelluft motion and a phenomenon they described as "alveolar stunning," whereby alveoli maintained an inflated state but did not appear to participate in ventilation.
The most severe dysfunction occurred in acid-induced ARDS and resulted in marked gas-exchange dysfunction. Although this phenomenon appeared to be transient nonetheless it suggests that a more complex array of pathophysiologic mechanisms might be present in ARDS than previously appreciated.

The significantly lower $\mathrm{V}_{\mathrm{D}} / \mathrm{V}_{\mathrm{T}}$ and mortality rate in trauma-associated ARDS is consistent with other studies that have found a lower mortality in trauma-associated ARDS. ${ }^{22}$ Given the widely diverse mechanisms of traumatic injury (eg, isolated brain injury vs chest trauma), it was unexpected that our data did not demonstrate salient differences in dead space by traumatic etiology, and although $\mathrm{V}_{\mathrm{D}} / \mathrm{V}_{\mathrm{T}}$ was highest in those with multiple-organ system injuries (ie, 4 or more), the magnitude of $\mathrm{V}_{\mathrm{D}} / \mathrm{V}_{\mathrm{T}}$ generally did not approach that observed in other etiologies. This raises the question of whether trauma-associated ARDS is a relatively self-limiting form of lung injury, as others have suggested. ${ }^{3}$

Finally, the robust relationship between $\mathrm{V}_{\mathrm{D}} / \mathrm{V}_{\mathrm{T}}$ and mortality in this study, as in previous reports, may in part be explained by the fact that $\mathrm{CO}_{2}$ is approximately 20 times more diffusible across tissues than $\mathrm{O}_{2}$, thus making it highly perfusion-sensitive. ${ }^{2}$ Therefore, impaired $\mathrm{CO}_{2}$ excretion probably reflects the magnitude of ventilation-perfusion mismatching in ARDS (a potential signifier of microvascular injury, regional lung overdistention, and perhaps pronounced pendelluft motion and stunning at the alveolar level). In addition, $\mathrm{V}_{\mathrm{D}} / \mathrm{V}_{\mathrm{T}}$, as determined by the Enghoff-Bohr equation, is influenced by the degree of intrapulmonary shunt. ${ }^{23}$ Thus, $\mathrm{V}_{\mathrm{D}} / \mathrm{V}_{\mathrm{T}}$ may provide a more comprehensive representation of overall lung injury. In turn, as the severity of ARDS increases, so too does the likelihood of developing ventilatorinduced lung injury, cor pulmonale, multi-organ system failure, and ventilator-associated pneumonia all of which increase mortality risk. Therefore, $\mathrm{V}_{\mathrm{D}} / \mathrm{V}_{\mathrm{T}}$ should be understood as simply a marker by which to assess both the severity of the syndrome and its response to therapy. In other words, the goal of some therapies in ARDS should not be to reduce $\mathrm{V}_{\mathrm{D}} / \mathrm{V}_{\mathrm{T}}$ per se, but to reduce alveolar overdistention and restore functional residual capacity to the extent possible, which in turn is reflected in improved $\mathrm{V}_{\mathrm{D}} / \mathrm{V}_{\mathrm{T}}$.

The principle limitations of this study are the retrospective design and single-center enrollment. Despite these limitations, it is the largest observational study of $\mathrm{V}_{\mathrm{D}} / \mathrm{V}_{\mathrm{T}}$ in ARDS using lung-protective ventilation to date. The different etiologies of ARDS are well represented and evenly distributed. Moreover, the results of this study are consistent with the findings of previous studies ${ }^{1,6,7,24-29}$ that $\mathrm{V}_{\mathrm{D}} / \mathrm{V}_{\mathrm{T}}$ is a particularly robust signifier of mortality risk in ARDS.

\section{Conclusions}

In summary, in early ARDS, $\mathrm{V}_{\mathrm{D}} / \mathrm{V}_{\mathrm{T}}$ differs according to both etiology and injury severity according to the new Berlin definition. $\mathrm{V}_{\mathrm{D}} / \mathrm{V}_{\mathrm{T}}$ tends to be higher in direct causes 


\section{Dead-Space Fraction and Mortality in ARDS}

of ARDS (eg, aspiration and pneumonia) as compared with indirect causes (eg, sepsis). With the exception of mild ARDS, $\mathrm{V}_{\mathrm{D}} / \mathrm{V}_{\mathrm{T}}$ was significantly elevated in nonsurvivors compared with survivors. In multivariate logistic regression modeling, after controlling for all other variables, $\mathrm{V}_{\mathrm{D}} / \mathrm{V}_{\mathrm{T}}$ had the strongest association with mortality risk.

\section{REFERENCES}

1. Nuckton TJ, Alonso JA, Kallet RH, Daniel BM, Pittet JF, Eisner MD, Matthay MA. Early elevation in dead-space ventilation is associated with mortality risk in patients with acute respiratory distress syndrome. N Engl J Med 2002;346(17):1281-1286.

2. Kallet RH. Measuring dead-space in acute lung injury. Minerva Anestesiol 2012;78(11):1297-1305.

3. Dicker RA, Morabito DJ, Pittet JF, Campbell AR, Mackersie RC. Acute respiratory distress syndrome criteria in trauma patients: why the definitions do not work. J Trauma 2004;57(3):522-526; discussion 526-528.

4. Calfee CS, Janz DR, Bernard GR, May AK, Kangelaris KN, Matthay MA, et al. Distinct molecular phenotypes of direct vs indirect ARDS in single-center and multicenter studies. Chest 2015;147(6):1539-1548.

5. Luo L, Shaver CM, Zhao Z, Koyama T, Calfee CS, Bastarache JA, Ware LB. Clinical predictors of hospital mortality differ between direct and indirect acute respiratory distress syndrome. Chest 2017; 151(4):755-763.

6. Kallet RH, Alonso JA, Pittet JF, Matthay MA. Prognostic value of the pulmonary dead-space fraction during the first six days of acute respiratory distress syndrome. Respir Care 2004;49(9):1008-1014.

7. Kallet RH, Zhuo H, Liu KD, Calfee CS, Matthay MA, National Heart Lung and Blood Institute ARDS Network Investigators. The association between physiologic dead-space fraction and mortality in patients with acute respiratory distress syndrome enrolled into prospective, multicentered clinical trial. Respir Care 2014;59(11):1611-1618.

8. ARDS Definition Taskforce, Ranieri VM, Rubenfeld GD, Thompson BT, Ferguson ND, Caldwell E, et al. Acute Respiratory Distress Syndrome: The Berlin Definition. JAMA 2012;307(23):2526-2533.

9. Acute Respiratory Distress Syndrome Network, Brower RG, Matthay MA, Morris A, Schoenfeld D, Thompson BT, Wheeler A. A trial of traditional tidal volume versus lower tidal volume ventilation in acute lung injury and acute respiratory distress syndrome. N Engl J Med 2000;342(18):1301-1308.

10. Brower RG, Lanken PN, MacIntyre N, Matthay MA, Morris A, Ancukiewicz M, et al. Higher versus lower positive end-expiratory pressures in patients with the acute respiratory distress syndrome. N Engl J Med 2004;351(4):327-336.

11. Bernard GR, Artigas A, Brigham KL, Carlet J, Falke K, Hudson L, et al. Report of the American-European consensus conference on acute respiratory distress syndrome: definitions, mechanisms, relevant outcomes, and clinical trials coordination. Am J Respir Crit Care Med 1994;149(3 Pt 1):818-824.

12. Kallet RH, Daniel BM, Garcia O, Matthay MA. Accuracy of physiologic dead space measurements in patients with acute respiratory distress syndrome using volumetric capnography: comparison with the metabolic monitor method. Respir Care 2005;50(4):462-467.

13. Enghoff H. Volumen inefficax: Bemerkungen zur frage des schädlichen raumes. Upsala Lakareforen Forh 1938;44:191-218.
14. Amato MB, Meade MO, Slutsky AS, Brochard L, Costa EL, Schoenfeld DA, et al. Driving pressure and survival in the acute respiratory distress syndrome. N Engl J Med 2015;372(8):747-755.

15. Ortiz RM, Cilley RE, Bartlett RH. Extracorporeal membrane oxygenation in pediatric respiratory failure. Pediatr Clin North Am 1987; 34(1):39-46.

16. Murray JF, Matthay MA, Luce JM, Flick MR. An expanded definition of the adult respiratory distress syndrome. Am Rev Respir Dis 1988;138(3):720-723.

17. Le Gall JR, Lemeshow S, Saulnier F. A new Simplified Acute Physiology Score (SAPS II) based on a European-North American multicenter study. JAMA 1993;270(24):2957-2963.

18. Knaus WA, Draper EA, Wagner DP, Zimmerman JE. Apache II. A severity of disease classification system. Crit Care Med 1985;13(10): 818-829.

19. Kallet RH, Jasmer RM, Pittet JF, Tang JF, Campbell AR, Dicker RA, et al. Clinical implementation of the ARDS Network protocol is associated with reduced hospital mortality compared to historical controls. Crit Care Med 2005;33(5):925-929.

20. Boissier F, Katsahian S, Razazi K, Thille AW, Roche-Campo F, Leon R, et al. Prevalence and prognosis of cor pulmonale during protective ventilation for acute respiratory distress syndrome. Intensive Care Med 2013;39(10):1725-1733.

21. Tabuchi A, Nickles HT, Kim M, Semple JW, Koch E, Brochard L, et al. Acute lung injury causes asynchronous alveolar ventilation which can be corrected by individual sighs. Am J Respir Crit Care Med 2016;193(4):396-406.

22. Eisner MD, Thompson T, Hudson LD, Luce JM, Hayden D, Schoenfeld $\mathrm{D}$, et al. Efficacy of low tidal volume ventilation in patients with different clinical risk factors for acute lung injury and the acute respiratory distress syndrome. Am J Respir Crit Care Med 2001;164(2):231-236.

23. Waltuck BL. The Bohr equation. Anesthesiology 1970;32(5):472473.

24. Lucangelo U, Bernabè F, Vatua S, Degrassi G, Villagrà A, Fernandez R, et al. Prognostic value of different dead space indices in mechanically ventilated patients with acute lung injury. Chest 2008;133(1):62-71.

25. Cepkova M, Kapur V, Ren X, Quinn T, Zhuo H, Foster E, et al. Pulmonary dead space fraction and pulmonary artery systolic pressure as early predictors of clinical outcome in acute lung injury. Chest 2007;132(3):836-842.

26. Raurich JM, Vilar M, Colomar A, Ibáñez J, Ayestarán I, PérezBárcena J, Llompart-Pou JA. Prognostic value of the pulmonary dead-space fraction during early and intermediate phases of acute respiratory distress syndrome. Respir Care 2010;55(3):282-287.

27. Ong T, McClintock DE, Kallet RH, Ware LB, Matthay MA, Liu KD. Ratio of angiopoietin-2 to angiopoeitin-1 as a predictor of mortality in acute lung injury patients. Crit Care Med 2010;38(9):1845-1851.

28. Phillips CR, Chesnutt MS, Smith SM. Extravascular lung water in sepsis-associated acute respiratory distress syndrome: Indexing with predicted body weight improves correlation with severity of illness and survival. Crit Care Med 2008;36(1):69-73.

29. Fengmei G, Jin C, Songqiao L, Congshan Y, Yi Y. Dead-space fraction changes during positive end-expiratory pressure titration following lung recruitment in acute respiratory distress syndrome patients. Respir Care 2012;57(10):1578-1585.

This article is approved for Continuing Respiratory Care Education credit. For information and to obtain your CRCE

(free to AARC members) visit www.rcjournal.com

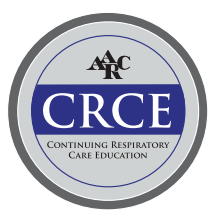

